\title{
Multicystic Dysplastic Kidney
}

National Cancer Institute

\section{Source}

National Cancer Institute. Multicystic Dysplastic Kidney. NCI Thesaurus. Code C123031.

Abnormal development of the kidney that is characterized by atretic ureter, multiple cysts

of different sizes that are separated by dysplastic parenchyma, and complete lack of function. 